\title{
Hydrogen isotope composition of $n$ - alkanes generated during anhydrous pyrolysis of peats from different environments
}

\section{YI DUAN}

Northwest Institute of Eco-Environment and Resources,

Chinese Academy of Sciences and Gansu Provincial Key Laboratory of Petroleum Resources, Lanzhou, Gansu, China (duany@1zb.ac.cn).

The variation and its level of hydrogen isotopic composition of individual $n$-alkanes in sediments from different latitudes and climatic environments from immature to post mature are still unclear. We carried out anhydrous closed pyrolyses on herbaceous peats from different latitude and climatic environments. The results revealed that $n$ alkanes pyrolyzed by peat in low latitude tropical region generally have low CPI and high ACL values compared with those in high latitude cold region, and the ACL value decreased with thermal evolution. Therefore, it should be prudent to use the CPI and ACL value to study the maturity of the organic matter and the paleoclimate environment, respectively. It was also found that the distribution pattern of $\delta \mathrm{D}$ value of $n$-alkanes between the original and pyrolysis samples was similar from the pre-oil generation to the primary oil generation stages, and was significantly different during the post-oil generation stage. We observed that at the $450{ }^{\circ} \mathrm{C}$, the maximum difference in average $n$-alkane $\delta \mathrm{D}$ values and $\delta \mathrm{D}$ values of individual $n$-alkanes between the pyrolysis and original samples was $108 \%$ and $165 \%$, respectively. The $\mathrm{D}$ enrichment of pyrolysis $n$-alkanes relative to original sample should be derived from isotopic thermodynamic fractionation. The study also found that $n$ alkanes pyrolyzed by peat from the high latitude cold region have a light hydrogen isotopic composition compared with those from the low latitude tropic, and the difference was $67 \%$ in the pre-oil generation stage, was $44 \%$ in the incipient oil generation to-main oil stages, and was very small in the post-oil generation stage. The relationships between the $\delta \mathrm{D}$ values of different $n$-alkanes pyrolyzed by peats from the two latitude regions and the relationship between the average $\delta \mathrm{D}$ and ACL values of $n$-alkanes were established. These provide sedimentary $n$-alkane hydrogen isotopic reference data to identify ancient climatic environment, organic matter sources and their maturity levels.

Acknowledgements: This study was supported by the National Natural Science Foundation of China (Grant Nos. 41772108 and 41972110). 